Int. J. Dev. Biol. 60: 289-296 (2016)

doi: $10.1387 / \mathrm{ijdb} .160163 \mathrm{at}$

\title{
Reprogramming of somatic cells and nuclei by Xenopus oocyte and egg extracts
}

\author{
ALEXANDER A. TOKMAKOV ${ }^{1,2, *}$, TETSUSHI IWASAKI ${ }^{2}$, KEN-ICHI SATO ${ }^{1}$ and SHINJI KAMADA ${ }^{2}$ \\ ${ }^{1}$ Department of Molecular Biosciences, Kyoto Sangyo University, Kyoto and \\ ${ }^{2}$ Research Center for Environmental Genomics, Kobe University, Kobe, Japan
}

\begin{abstract}
Differentiated somatic cells and nuclei can be reprogrammed to a pluripotent undifferentiated state in the cytoplasm of oocytes and eggs. The ability of the gamete cells to induce reprogramming is not species-specific, so the extracts prepared from the oocytes and eggs of the African clawed frog Xenopus laevis can reprogram somatic mammalian cells. Thus, Xenopus egg extract-mediated reprogramming may constitute an alternative or complement other experimental reprogramming approaches, such as nuclear transfer, cell fusion, and transcription factor transduction. Here, we discuss the major reprogramming events induced by the extracts in somatic nuclei and cells, including remodeling of nuclear structure, replacement of somatic proteins with their embryonic counterparts, epigenetic modification of DNA and histones, transcriptional reprogramming, and initiation of DNA replication. We also address the advantages and limitations of the extract-based reprogramming approach.
\end{abstract}

KEY WORDS: Xenopus laevis, oocyte, egg, cell extract, somatic cells, reprogramming

\section{Introduction}

Fertilized eggs from sexually reproducing species are totipotent cells; they can develop into complete organisms, containing all types of differentiated tissue cells. Also, in some cases, enucleated eggs injected with differentiated somatic nuclei are able to produce complete organisms. However, somatic cells by themselves are not capable of generating a complete organism. Hence, it was concluded that the nuclei of differentiated somatic cells are remodeled and reprogrammed in the zygotic cytoplasm to allow embryo development. Nuclear reprogramming following nuclear transfer has been successful in many species. Historically, the procedure of nuclear transplantation was established in the 1950s and 1960s using frog eggs and oocytes (Briggs and King, 1952; Elsdale et al., 1960; Gurdon, 1962a). The advantage of this system is ample availability of amphibian eggs and oocytes and their large size, exceeding 1000-fold the volume of mammalian eggs which makes injection of somatic nuclei less technically demanding. Two frog species, Rana pipiens and Xenopus laevis, were initially used in the nuclear transfer experiments. Before the transplantation, eggs are enucleated either manually (Rana pipiens) or by ultraviolet irradiation (Xenopus laevis), and somatic nuclei or cells are injected with a transfer glass micropipette. Amphibian eggs do not require activation after the nuclear transfer, as they are activated by micro- pipette pricking. Complete nuclear reprogramming of differentiated somatic nuclei transplanted to Xenopus eggs was witnessed by the finding that some eggs injected with nuclei from intestinal epithelial cells of tadpoles undergo normal early embryonic development (Gurdon, 1962a; Gurdon and Uehlinger, 1966). Also, nuclei from various cultured cells derived from adult frog tissues, including heart, skin, lung, etc., could yield normal feeding tadpoles, albeit with a low success rate not exceeding several percents (Laskey and Gurdon, 1970). It was concluded that the ratio of normal development decreases as nuclei are taken from increasingly differentiated cells. Thus, resulting reprogramming events vary depending on cell types. It was also revealed that the cross-species nuclear transfer between Rana pipiens and Xenopus laevis results in embryonic death (Gurdon, 1962b). Importantly, despite the failure of normal embryo development, a number of nuclear reprogramming events specified further in this paper still occur in cross-species nuclear transfer experiments. Thus, Xenopus oocytes and eggs were used to reprogram differentiated cells and nuclei from various species, including mammals.

Markedly, oocyte and eggs represent essentially different gamete cells, which allow to study different aspects of nuclear reprogram-

Abbreviations used in this paper: CSF, cytostatic factor; MPF, maturation promoting factor.

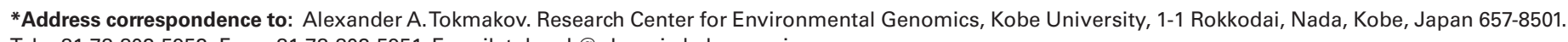
Tel: +81-78-803-5953. Fax: +81-78-803-5951. E-mail: tokmak@ phoenix.kobe-u.ac.jp

Accepted: 19 May 2016.

ISSN: Online 1696-3547, Print 0214-6282 
ming and dedifferentiation. Fully grown Xenopusoocytes, reaching $1.2 \mathrm{~mm}$ in diameter, are naturally arrested in prophase of the first meiotic division at the G2/M boundary. They have the tetraploid nucleus, intact nuclear envelope, partially decondensed chromatin, high activity of transcription and low activity of the key mitotic regulators, maturation promoting factor (MPF) and cytostatic factor (CSF) (Fig. 1). MPF consists of cyclin B and cyclin-dependent protein kinase Cdk1. The proto-oncogenic protein kinase Mos, which is present only in meiosis and disappears after fertilization, (Sagata et al., 1989) and the active MAPK pathway are the major components of CSF. Immature oocytes are not competent to fertilization and can rest in the ovaries for many months. Oocytes accumulate vast amounts of different maternal RNAs and proteins, including nuclear remodeling factors, needed for early embryonic development before the start of zygotic transcription. In fact, oocytes are much more active in general transcription than any other cell type (Davidson, 1986). In the nuclear reprogramming experiments using frog oocytes, somatic nuclei are usually injected into the germinal vesicle (GV), the specialized and enlarged nucleus of oocytes reaching $400 \mu \mathrm{m}$ in diameter. Up to several hundred somatic nuclei can be injected into a single Xenopusoocyte. Transplanted somatic nuclei become transcriptionally reprogrammed in the GV within hours and days, making this approach useful for molecular and kinetic delineation of transcriptional reprogramming. In contrast to oocytes, eggs have a low activity of transcription. The term "eggs" in frogs is conventionally used for ovulated mature oocytes. The steroid hormone progesterone, secreted from the follicle cells surrounding oocytes, induces meiotic transition, resulting in the formation of fertilization-competent haploid eggs. After the completion of maturation, Xenopus eggs are arrested awaiting fertilization in the metaphase of the second meiotic division due to the high activity of MPF and CSF (Fig. 1). Fertilization or parthenogenetic stimulation inactivates CSF and MPF and releases metaphase II arrest. Calcium-dependent degradation of cyclin B is thought to trigger the disruption of positive feedback between MPF and CSF (reviewed in Tokmakov et al., 2014). Mature Xenopus eggs and dividing embryos are transcriptionally inactive until the mid-blastula transition (MBT), occurring after the $12^{\text {th }}$ embryonic division, when transcription of the zygotic genome starts. Early embryonic cell cycles before the MBT rapidly oscillate between DNA synthesis and mitosis with no detectable G phases (Fig. 1; Newport and Kirschner, 1982a,b). Thus, activated eggs and dividing early embryos are active in DNA replication rather than in transcription, and the remodeling of somatic nuclei injected into Xenopus eggs is primarily associated with the induction of DNA synthesis and mitotic transition.

Recently, cell-free Xenopus oocyte and egg extracts have been employed for reprogramming of somatic cells and nuclei to a pluripotent state. The extracts can recapitulate meticulously a number of fundamental cellular processes. In fact, many of the control mechanisms that operate in maturing oocytes, fertilized eggs and early embryos have first been established in the frog model. Protocols of extract preparation have been developed for studying various physiological processes, such as apoptosis, nuclear transport, nuclear disassembly, nucleosome formation, cell cycle transition, mitotic spindle assembly, etc. The procedures of extract preparation vary in details, depending on the nature of the studied process. Commonly, oocytes and eggs are crushed by centrifugation at $>10,000 \mathrm{~g}$ for $15 \mathrm{~min}$ at $4^{\circ} \mathrm{C}$ in the presence of reducing agents (2-mercaptoethanol or dithiothreitol) and protease inhibitors, such as aprotinin, leupeptin, and pepstatin. Cytochalasin $B$ is also included to reduce the viscosity of the extracts. Re-centrifugation under appropriate conditions is used to obtain low-speed and high-speed cytoplasmic fractions. The resulting extracts are supplemented with glycerol (2-5\%), frozen in aliquots in liquid nitrogen and stored at $-80^{\circ} \mathrm{C}$ until use. Cell-free experimental format provides great advantages for dissecting regulatory events of the developmental processes. It allows direct access to and targeting of the individual molecular components involved in the regulation of these processes using specific inhibitors and activators. Large volumes (several milliliters) of highly synchronized homogenous extract can be produced from the oocytes and eggs of a single frog. In the case of somatic cell reprogramming, Xenopus oocyte and egg extracts have been used to pinpoint the essential molecular components necessary for nuclear reprogramming. The extracts proved to be especially helpful in identifying the factors that are required for nuclear remodeling, DNA replication, transcriptional changes, exchange of somatic chromosomal proteins, and epigenetic modifications of DNA and histones.

It should be noted that reprogramming of somatic cells, in contrast to nuclei, requires plasma membrane permeabilization because large molecules, such as proteins, cannot easily be transported from extracts to the cytoplasm via the plasma membrane. Cells are usually permeabilized with streptolysin $\mathrm{O}$ or digitonin and resealed by the addition of calcium, so that they can be further cultured to study transcriptional changes and dedifferentiation during cell culture. Analysis of reprogramming in reversibly permeabilized and non-permeabilized porcine fibroblasts treated with Xenopus

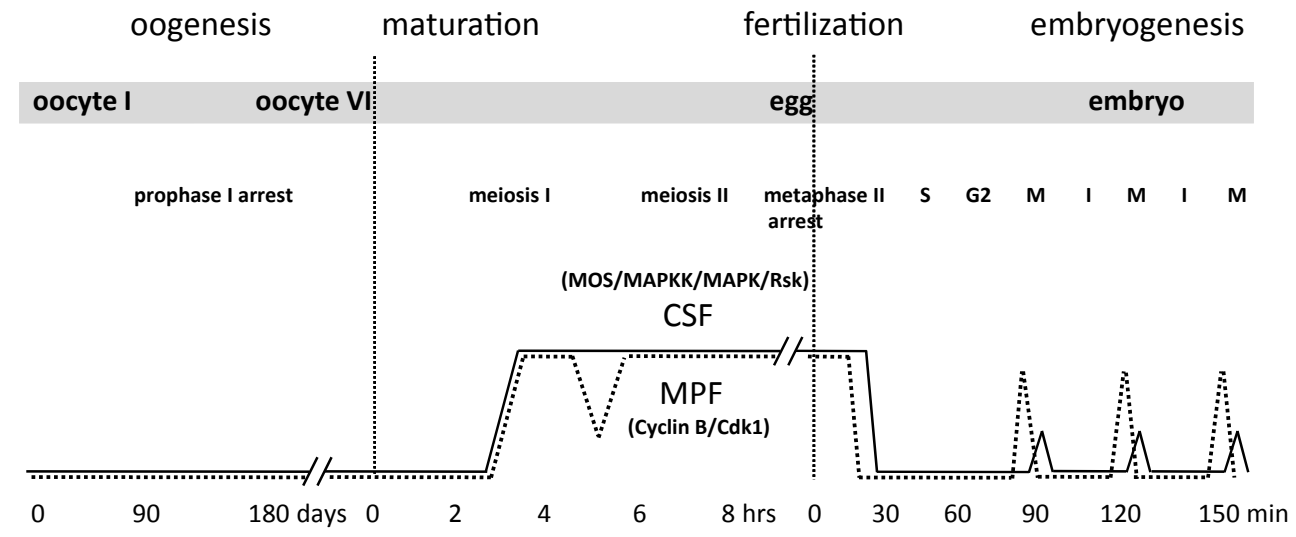

Fig. 1. Progression from Xenopusoocytes to early embryos. The major developmental processes, such as oogenesis, meiotic maturation, fertilization, early embryo divisions and their timing are indicated. Cell cycle stages and activity of the key cell cycle regulators, cytostatic factor (CSF) and maturation-promoting factor (MPF), are also shown (see text for details). 
egg extracts demonstrated that some reprogramming events may be induced even in non-permeabilized cells, suggesting that the necessary factors can also enter the cells via endocytosis. However, non-permeabilized cells usually show reduced efficiency of reprogramming after extract treatment (Miyamoto et al., 2007). On the other hand, reprogramming efficiency in the experiments using permeabilized cells is highly variable, because it is difficult to control the level of membrane permeabilization. Notably, high concentrations of digitonin permeabilize both the plasma membrane and nuclear envelope. Permeabilized nuclei were also employed to analyze nuclear reprogramming by Xenopusegg extracts (Kikyo et al., 2000; Gonda et al., 2003).

In the present work, we summarize our current knowledge about the major reprogramming events induced by Xenopus egg and oocyte extracts in somatic nuclei and cells. They include remodeling of nuclear structure, transcriptional reprogramming, initiation of DNA replication, epigenetic modification of DNA and histones, and replacement of somatic proteins with their embryonic counterparts, as outlined in Fig. 2. Following sections of this review address the individual reprogramming events in detail. For the purpose of comparison, we also refer to other experimental reprogramming techniques, especially to the technique of nuclear transfer, and discuss the advantages and limitations of the extractbased reprogramming approach.

\section{Remodeling of nuclear structure}

Nuclear reprogramming is associated with dramatic remodeling of nuclear ultrastructure and morphology, reminiscent of changes that happen to sperm at fertilization. Major morphological changes associated with the remodeling of transplanted nuclei in the cytoplasm of Xenopus oocytes and eggs include nuclear swelling, rearrangement of the nuclear envelope, chromatin reorganization, and dissolution of nucleoli. One of the most visible manifestations of nuclear remodeling is extensive swelling of nuclei. Mammalian nuclei transferred into Xenopus oocytes undergo up to several hundred times increase in volume in the course of several days (Gurdon, 1976). Nuclear enlargement is accompanied by the dispersion of chromatin, increase in the rate of RNA synthesis, loss of protein from transplanted nuclei, and uptake of histone and non-histone proteins from oocyte cytoplasm (Gurdon et al., 1976). The decondensed interphase chromatin represents one of the hallmarks of reprogramming observed in somatic nuclei introduced into oocytes or oocyte extracts arrested in the first meiotic prophase with low activity of MPF and CSF (Gurdon, 1968; Tamada et al., 2006). It is assumed that chromatin loosening facilitates the access of cellular transcriptional machinery to repressed genes, because swollen nuclei in oocytes show more active transcription than not swollen (Gurdon et al., 1979). Importantly, the oocyte and egg cytoplasm exhibit quite different nuclear remodeling activities. The transfer of somatic nuclei into MIl-arrested eggs results in the breakdown of the nuclear envelope and premature chromatin condensation due to high activity of MPF. This factor controls phosphorylation of nuclear pore proteins, lamin proteins, and inner nuclear membrane proteins, leading to changes in pore permeability, disassembly of the nuclear lamina, and breakdown of the nuclear envelope (reviewed in Prunuske and Ullman, 2006; Guttinger et al., 2009). Destabilization of the nuclear envelope allows direct interaction of somatic chromatin with egg-specific remodeling factors. Condensed chromatin rearranges after the loss of MPF activity in metaphase, accompanied by the formation of nuclear envelope and functional nuclei. Chromatin reorganization is thought to be a primary event of somatic nuclei reprogramming related to DNA replication and transcriptional regulation. In addition to epigenetic modifications and protein exchange (see following sections), the remodeling of the nuclear envelope and chromatin reorganization contribute to transcriptional reprogramming and acquisition of the nuclear architecture similar to that found in undifferentiated cells.

Along the changes of overall nuclear morphology and chromatin organization, the nucleolus of somatic cells also undergoes dramatic remodelling during nuclear reprogramming. The nucleolus is the most prominent nuclear organelle responsible for ribosome biogenesis, including processing and synthesis of rRNA. Transcription of rRNA genes seems to be essential for maintaining nucleolar integrity (Simard, 1970). The functional nucleolus in somatic nuclei is composed of well-defined fibrillary and granular compartments containing rRNA-encoding genes, transcription factors, nascent rRNA, proteins engaged in rRNA processing and ribosome subunit formation (reviewed in Hernandez-Verdun, 2006). The nucleolus is reduced to a small nucleolar remnant in grown up oocytes. It is completely dissolved during oocyte maturation in meiosis and reappears after meiotic exit in the form of nucleolus precursor bodies. Subsequent nucleologenesis during early embryonic divisions leads to formation of a functional fibrillogranular nucleolus by the time of zygotic genome activation (reviewed in Ostrup et al., 2015). In accordance with these events the morphology of nucleoli changes in differentiated somatic cells incubated in the cytoplasm of oocytes and eggs. The nucleoli of somatic nuclei are rapidly disassembled in interphase eggs and reassembled again when transcription starts in early embryos, reproducing the natural nucleolar dynamics of early embryogenesis. For instance, more than $70 \%$ of Xenopus embryonic fibroblast XL2 nuclei loose definitive nucleoli and the remainder of the nuclei retain only a small nucleolar remnant after a two-hour incubation in S-phase egg extracts (Gonda et al., 2003). Furthermore, an early event of Xenopus egg extract-mediated nuclear reprogramming in somatic cells was shown to be the remodeling of ribosomal genes (Ostrup et al., 2011). It is mediated by a member of ATP-dependent chromatin remodelers, the nucleolar remodeling complex NoRC, which causes heterochromatin formation and transcriptional silencing (Strohner et al., 2004; Mayer et al., 2008). Nucleolar remodeling in this system involves a rapid and stable decrease in ribosomal gene transcription and promoter targeting of a NoRC component, the ATPase SNF2H. Previously, it was demonstrated that NoRC, comprising SNF2H and the nucleolar protein TIP5, recruits DNA methyltransferases, histone deacetylases, and histone methytransferases to the promoters of ribosomal RNA genes, triggering their transcriptional silencing (Strohner et al., 2001; Strohner et al., 2004). It has been proposed that nucleolar transformation can be used as a marker of chromatin reprogramming in various experimental approaches (Ostrup et al., 2015).

\section{Protein exchange}

It is thought that, at the molecular level, the reprogramming of somatic cells and nuclei in the cytoplasm of oocytes and eggs is mediated in large part by replacement of somatic proteins of differentiated nuclei with their embryonic counterparts. It was dem- 
onstrated that somatic nuclei transferred into Xenopus oocytes or eggs loose more than $80 \%$ of their original proteins within several hours, and cytoplasmic proteins migrate into transferred nuclei (Gurdon et al., 1976; Gurdon et al., 1979). The abundant proteins of the oocyte cytoplasm, such as embryo-specific histones, lamines, nucleoplasmin, etc., were found to be intensely incorporated into transferred nuclei. Thus, protein exchange between somatic nuclei and the cytoplasm of eggs and oocytes represents one of the major phenomena of reprogramming. Selective trafficking of macromolecules between the cytoplasmic and nuclear environments occurs through nuclear pore complexes of the nuclear envelope. In the metaphase egg extracts, chromosomal protein exchange is facilitated by the disruption of nuclear envelope due to high activity of MPF and CSF.

It was shown, by the real time monitoring of gene expression and chromatin protein exchange, that a loss of somatic $\mathrm{H} 1$ linker histone and incorporation of oocyte-specific B4 linker histone precede transcriptional reprogramming in somatic nuclei transferred to Xenopus oocytes. Furthermore, the loss of $\mathrm{H} 1$ histone is not required, but the incorporation of $\mathrm{B} 4$ histone is crucial for reactivation of the pluripotency genes, such as oct4 and sox2, during nuclear reprogramming (Jullien et al., 2010; Jullien and Gurdon 2011). It was proposed that the binding of oocyte-specific B4 linker histone represents a key event in the reprogramming of somatic nuclei transplanted to amphibian oocytes. Assembly of egg-specific histone B4 on porcine chromatin was also observed in Xenopus egg extracts (Miyamoto et al., 2007). It was demonstrated that the molecular chaperone nucleoplasmin plays an important role in the selective removal of linker histone variants $\mathrm{H} 1$ and $\mathrm{H} 1^{\circ}$ from somatic chromatin (Dimitrov and Wolffe, 1996). The acidic nuclear protein nucleoplasmin is present in Xenopus eggs at a very high concentration of $\sim 7 \mathrm{mg} / \mathrm{ml}$, and it was found to be involved in chromatin decondensation and dispersal (Leno et al., 1996; Tamada et al., 2006). Besides linker histones, other nuclear proteins show high levels of exchange during the first hours of reprogramming in the Xenopus oocyte and egg cytoplasm. They include various polypeptides, such as lamins, high mobility group (HMG) proteins, transcription repressor heterochromatin protein 1 (HP1), nuclear actin, acetylases and deacetylases of histones, DNA methyltransferases and demethylases, DNA replication machinery, cell cycle regulators, etc. (Kikyo and Wolffe, 2000). These components are loaded onto somatic chromatin from the abundant oocyte stock, replacing and supplementing their somatic counterparts already present in somatic cells. Their exchange is accompanied by an increase in chromatin mobility similar to that observed in pluripotent cells (Jullien et al., 2011). Notably, core histones, such as H3 and $\mathrm{H} 4$, do not display high levels of exchange at the beginning of nuclear reprogramming due to, probably, their intrinsically low mobility in the chromatin (Kimura and Cook, 2001).

As a result of protein exchange, oocyte and egg extracts fundamentally modify the nuclear lamina of somatic cells leading to structural changes in their nuclei with implications for transcriptional activity. Lamin A/C, but not lamin B2, is removed from somatic cells incubated in oocyte and post-meiotic egg extracts for 3 hours. Lamin A/C removal was found to be independent of MPF activity. The energy-dependent incorporation of embryonic-specific lamin III, the major lamin component available in egg extracts, was observed into nuclear envelopes of somatic cells incubated in egg extracts, however the lamin III inclusion could not be detected in oocyte extracts (Alberio et al., 2005; Miyamoto et al., 2007). It was suggested that lamin A/C dissolution may be promoted by kinase activities in the extracts, whereas lamin III incorporation is driven by its nuclear localization signal (Peter et al., 1990; Doring and Stick, 1990).

Anumber of other proteins, which translocate from the oocyte/egg cytoplasm and play important roles in the reprogramming of somatic nuclei, have been identified. It was found, using S-phase Xenopus egg extract, that a single protein, FRGY2a/b, can trigger reversible disassembly of nucleoli, a hallmark of chromatin reprogramming (see the section "Remodeling of nuclear morphology"). This finding is quite surprising, considering that the nucleolus is maintained by numerous RNA-protein and protein-protein interactions. FRGY2a/b protein is expressed specifically in Xenopus oocytes and early embryos until the gastrula stage (Gonda et al., 2003). Similarly, it was shown that nuclear reprogramming of permeabilized human somatic cells, such as human primary leukocytes and 293T cells, by Xenopus egg extract requires the chromatin remodeling ATPase BRG1 (Hansis et al., 2004). Notably, reprogramming in this system was incomplete because the reprogrammed leukocytes had only a limited life span and did not express pluripotent surface antigens. Another chromatin-remodeling ATPase, ISWI-D is also implicated in nuclear reprogramming. The protein was shown to be required for the specific release of a TATA-box binding protein (TBP) from somatic nuclei incubated in Xenopus oocyte extracts, a process accompanied by chromatin condensation (Kikyo et al., 2000). It has been concluded that ATPase-dependent remodeling may act in concert with transcriptional reprogramming to achieve pluripotency in somatic mammalian cells.

Interestingly, although protein exchange is a universal process involving a large number of oocyte and egg proteins, it is suggested that the provision of maternal gene-specific transcription factors is not a general transcription reprogramming mechanism in oocytes and eggs, and most genes are probably regulated by a nonspecific transcriptional machinery (Gurdon and Wilmut, 2011). Of special interest might be the basal oocyte-specific transcription apparatus comprising TFIla/b-like factor (ALF) and TATA-box-binding protein 2 (TBP2). The latter was shown to replace somatic TBP from association with chromatin (Kikyo et al., 2000; D'Alessio et al., 2009). In addition to general transcriptional regulators, the proteins related to epigenetic modifications of DNA and histones are widely involved in the transcriptional reprogramming of somatic nuclei in the oocyte and egg cytoplasm, as specified in the following section.

\section{Epigenetic modifications of DNA and histones}

DNAmethylation and post-translational modifications of histones have been implicated in chromatin remodeling and transcriptional reprogramming. DNA methylation on cytosine is a universal epigenetic mark associated with gene suppression. The control regions of individual genes inactive in somatic cells are heavily methylated, which contributes to their silencing. DNA methylation is thought to be responsible for mammalian X-chromosome inactivation, genomic instability, and imprinting (reviewed in Bird, 2002; Niehrs, 2009). DNA methylation is epigenetically stable in differentiated somatic cells, however it is overwritten in gametes and early embryos. Notably, the epigenetic state of somatic chromatin was found to be modified after nuclear transfer or incubation in oocyte and egg extracts. It was reported that the treatment of somatic cells with 
Xenopus egg extract reduced global DNA methylation of donor cells and increased the success rate of following nuclear transfer embryo development (Yang et al., 2012). Demethylation of oct4 gene promoter, preceding transcriptional reprogramming, was observed in somatic nuclei transplanted to non-dividing Xenopus oocytes. This demethylation affects $\mathrm{mCpG}$ sites proximal to the promoter (Simonsson and Gurdon, 2004). Epigenetic marks in somatic chromatin, including DNA methylation, were shown to be reversed by amphibian oocyte extracts to resemble those in pluripotent nuclei (Bian et al., 2009). Evidently, eggs and oocytes possess the factors that promote demethylation, which is required for transcriptional reactivation of silenced genes in embryogenesis. Some of them have been revealed in recent studies. It was shown that the growth arrest and DNA-damage-inducible protein 45 alpha (Gadd45a), a protein involved in maintenance of genomic stability and DNA repair, plays an important role in DNA demethylation. Gadd45a specifically localizes to the site of demethylation during active demethylation of oct4 in Xenopus oocytes and reverses epigenetic gene silencing by promoting DNA repair that erases methylation marks (Simonsson and Gurdon, 2004; Barreto et al., 2007). Other protein components of the base excision and nucleotide excision repair processes (BER and NER) are also involved in active DNA demethylation (Niehrs, 2009). In addition, a Zn-dependent activation-induced cytidine deaminase (AID) has been implicated in DNA demethylation. It was reported that AIDdependent DNA demethylation is important for reprogramming to a pluripotent state in mammals (Bhutani et al., 2010; Popp et al., 2010). Furthermore, in mouse eggs and early embryos, the TET enzymes were shown to promote active DNA demethylation via hydroxylation of methylated cytosines. The balance between hydroxymethylation and methylation was proposed to be linked to pluripotency and lineage commitment in mouse ES cells and during differentiation (Tahiliani et al., 2009; Ficz et al., 2011).

Another mechanism of epigenetic reprogramming of somatic chromatin in oocytes, eggs, and their extracts involves post-translational modification (PTM) of histones. Alongside the replacement of somatic linker histones with their embryonic counterparts, as described above in the "Protein exchange" section, numerous PTMs of nucleosome core histones were implicated in the chromatin reprogramming. For example, reprogramming of somatic nuclei transplanted into Xenopus oocytes was reported to be accompanied by increased phosphorylation, increased methylation, and rapidly decreased acetylation of several amino acids in $\mathrm{H} 3$ histone. Specifically, methylation of histone $\mathrm{H} 3$ at Lys 4 was found to be associated with transcriptional activation of somatic nuclei by Xenopus oocytes; its timing correlated with pluripotency gene activation (Murata et al., 2010). In another study, deacetylation of histone $\mathrm{H} 3$ at Lys 9 was detected in nonpermeabilized somatic cells incubated in Xenopus egg extracts (Miyamoto et al., 2007). The extracts were reported to contain histone deacetylases, and deacetylation is thought to stabilize nucleosomal organization, leading to decrease of transcriptional activity (Ryan et al., 1999; Rice and Allis, 2001). It was suggested that deacetylation of histone $\mathrm{H3}$ at Lys 9 may be involved in erasing epigenetic memory of somatic cells to prepare chromatin for following site-specific acetylation in differentiating cells (Miyamoto et al., 2007). Furthermore, it was shown that the core histones $\mathrm{H} 2 \mathrm{~A}$ and $\mathrm{H} 4$ of somatic nuclei are phosphorylated in the Xenopusegg cytoplasm (Dimitrov and Wolffe, 1996). Also, phosphorylation of histone H3 at Ser 10 was observed in the nuclei of mammalian somatic cells incubated in Xenopus oocyte extracts. Aurora B kinase was found to be responsible for this phosphorylation (Murata et al., 2010). Admittedly, the exact role of individual histone PTMs in the chromatin reprogramming is not understood, however, it was proposed that, in general, histone modifications can serve to target active DNA demethylation due to direct interaction of DNA methyltransferases and methylCpG-binding proteins with histone-modifying enzymes, such as histone methyltransferases and histone deacetylases (Niehrs, 2009). Thus, histone modifications bolster the chromatin state that promotes repair-mediated DNAdemethylation and gene activation. In accordance with this, it was found that the histone $\mathrm{H} 3$ variant, H3.3, associated with epigenetic memory of an active gene state in Xenopus nuclear transfer embryos, is enriched with the marks of active chromatin, such as Lys 4 methylation, Lys 9 acetylation, and Lys 79 methylation (McKittrick et al., 2004; Ng and Gurdon, 2008). Remarkably, histone modifications are often associated with the regulatory regions of pluripotency genes.

\section{Transcriptional reprogramming and initiation of DNA replication}

So far, no reports of complete transcriptional reprogramming in oocyte and egg extracts, leading to cell divisions and new cell types generation, have been presented. However, the transferred somatic nuclei undergo extensive transcriptional reprogramming in the extracts. Differentiated somatic cells express only limited subsets of genes related to the specific functions of these cells, as compared to oocytes and embryonic cells where most genes are available for transcription. Also, the capacity of differentiated cells to multi-round replication and cell division is much restricted. Thus, reprogramming of differentiated somatic cells to a pluripotent undifferentiated state requires extensive chromatin remodeling in order to enable gene transcription and DNA replication. It was found that somatic nuclei transplanted to grown-up frog oocytes arrested in the first meiotic prophase experience dramatic changes in gene expression, which take place in the absence of DNA replication and cell division. On the other hand, the nuclei transferred to matured Xenopus eggs arrested in the second meiotic metaphase initiate DNA replication rather than transcriptional reprogramming (Gurdon and Wilmut, 2011). This finding can be attributed to the fact that rapid genome replication is a unique signature of early embryonic cell cycles in frogs. Notably, the first 12 embryonic divisions in fertilized Xenopus eggs occur in the absence of significant transcription, and only after passing this stage, called the mid-blastula transition, the zygotic transcription starts (Newport and Kirshner, $1982 a, b)$. In sum, the changes in the chromatin of differentiated cell seen in oocyte extracts are likely to be related to transcriptional reprogramming, whereas the changes observed in egg extracts concern mainly the initiation of DNA replication.

It was revealed that nuclear swelling and chromatin decondensation observed upon nuclear transfer (see the section "Remodeling of nuclear structure") directly correlate with RNAsynthesis, and this increase in transcription is associated with successful reprogramming (Gurdon et al., 1976). The nuclei of normal, non-dividing, terminally differentiated mammalian cells, such as adult mouse thymocytes and adult human blood lymphocytes, injected into the germinal vesicle of Xenopus oocytes can be directly reprogrammed to express the mammalian stem cell pluripotency marker oct4 at 
a rate comparable to that in mouse ES cells (Byrne et al., 2003). Transcriptional activation of other pluripotent genes, such as sox2 and nanog, was observed in several cell lines of permeabilized somatic cells injected into Xenopus oocytes. Interestingly, different kinds of somatic nuclei differ considerably in the extent of activation of the pluripotent genes (Halley-Stott et al., 2010). Reactivation of the pluripotent genes oct4, sox2 and nanog was also detected in permeabilized mammalian somatic cells incubated in the interphase extracts of activated Xenopus eggs. The pluripotent marker gene expression and colony formation were observed in the cultured extract-treated cells, suggesting their partial reprogramming to an embryonic state (Miyamoto et al., 2007; Miyamoto et al., 2008).

Markedly, oocytes can reactivate not only the pluripotency genes, such as oct4, sox2 and nanog, but also many other genes, especially those actively transcribed in oocytes. This pattern is similar to the genome-wide transcription observed in ES cells. Prophase I-arrested Xenopus oocytes were found to display a strong transcription-inducing activity. Particularly, transcription of several myogenic genes actively expressed in Xenopus oocytes was greatly induced in the permeabilized mammalian cells $\mathrm{C} 2 \mathrm{C} 12$ and $\mathrm{C} 3 \mathrm{H} 10 \mathrm{~T} 1 / 2$ transplanted to the oocytes, however the reactivated transcripts were mainly unspliced, suggesting low efficiency of splicing in the oocytes (Biddle et al., 2009). Interestingly, the myogenic factor MyoD, which is actively transcribed in Xenopus oocytes, as well as other known myogenic factors were not required to transcriptionally induce the studied muscle genes, indicating that the provision of maternal gene-specific transcription factors is not a general transcriptional reprogramming mechanism in the oocytes. Proteomic analysis of early reprogramming events in murine somatic cells incubated with Xenopus oocyte extracts revealed 69 nuclear proteins whose expression increased or decreased after the treatment. They included proteins of various functional classes, such as pluripotency markers, structural proteins, transcription factors, and translation regulators (Rathbone et al., 2013).

In contrast to oocytes, Xenopus eggs and egg extracts arrested in metaphase II do not support active transcription. It was reported that polymerase I- and polymerase II-dependent transcriptions are maintained in somatic cells incubated in Xenopus oocyte extracts, however both activities were suppressed in egg extracts (Alberio et al., 2005). In accordance with this, a rapid and stable decrease

\section{Remodeling of} nuclear structure

Enlargement of nucleus Chromatin reorganization Transformation of nucleolus

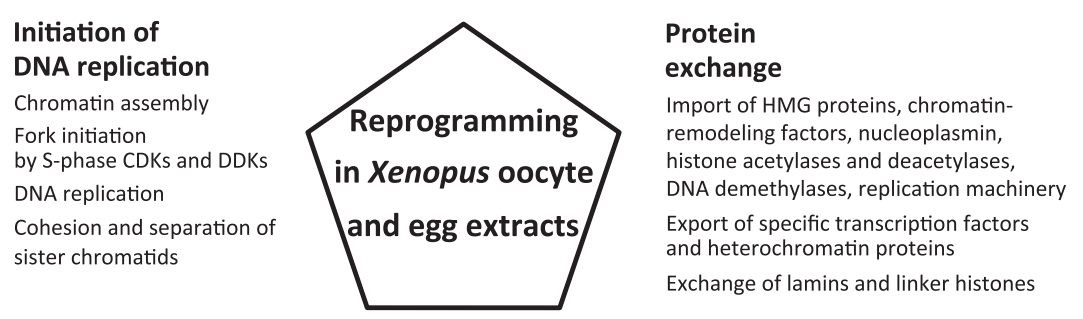

in ribosomal gene transcription, accompanied by large-scale reorganization of chromatin and nucleoli, was observed in human embryonic epithelial 293T cells treated with metaphase II-arrested extracts of Xenopus eggs (Ostrup et al., 2011). Unlike oocytes, eggs were found to be primarily active in DNA replication. DNA synthesis starts in Xenopus eggs about 30 minutes after activation and continues for approximately 30 minutes (Wangh et al., 1995). So, Xenopus eggs and egg extracts were utilized to identify the components needed for initiation of DNA replication, rather than for transcriptional reprogramming studies. It was demonstrated that a plasmid DNA replicates rapidly in activated Xenopus eggs if it was first injected and incubated in meiotically arrested eggs (Aquiles Sanchez et al., 1995). Accordingly, the nuclei from mature erythrocytes swell, replicate efficiently, and enter mitosis in interphase extracts, provided that the nuclei were first treated with trypsin, heparin, and the extracts prepared from meiotically arrested eggs (Wangh et al., 1995). The best replicating extracts in the study were produced from the eggs that have just reached G1/S boundary of the first cell cycle. The detailed study of DNA replication in Xenopus egg extracts revealed that they support a wide range of activities related to this process, including chromatin assembly, DNA duplication, cohesion and separation of sister chromatids, etc. (Arias and Walter, 2004; Gillespie et al., 2012). The extracts were especially successful in identifying pivotal molecules and mechanisms involved in the control of DNA replication. A key role of $S$ phase CDKs and Dbf4-dependent kinases (DDKs) in recruitment of replisome proteins and activation of Mcm2-7 helicase activity has been demonstrated (reviewed in Gonzalez et al., 2005). These mechanisms serve to ensure fast and faithful genome duplication during the first embryonic cell cycles.

\section{Conclusions and perspectives}

The data presented in this review demonstrate that differentiated somatic nuclei can be partially reprogrammed to a less differentiated state by Xenopus oocyte and egg extracts. A plethora of reprogramming events, as summarized in Fig. 2, occur in the nuclei and cells incubated in the extracts, including remodeling of nuclear structure and morphology, replacement of somatic proteins with their embryonic counterparts, epigenetic modification of DNA and histones, transcriptional reprogramming and initiation of genome replication. Admittedly, cell-free experimental format has some intrinsic limitations. Most markedly, quality of the extracts is quite variable. On the one hand, it depends on the quality of oocytes and eggs, which may differ greatly, depending on the season, frog age, conditions of frog maintenance, etc. On the other hand, even the small variations in the procedure of extract preparation affect dramatically their quality and capacity to recapitulate nuclear reprogramming events. Besides that, although egg and oocyte extracts recreate most closely intracellular environment of early embryo, they don't reflect the in vivo conditions in full. Although Xenopusoocyte and egg extracts are not able to induce the complete reprogramming of mammalian
Transcriptional reprogramming

Activation of pluripotent genes Genome-wide transcriptional activation
Epigenetic modifications DNA demethylation Histone PTMs
Fig. 2. Reprogramming events in Xenopus oocyte and egg extracts. The main nuclear reprogramming events observed in Xenopus oocyte and egg extracts are presented in diagram (see text for details). 
somatic cells and nuclei to a pluripotent state, they can be used to increase reprogramming efficiency in combination with other experimental approaches. For instance, pretreatment of donor cells with Xenopusegg extract before nuclear transfer was shown to increase the rate of successful embryo development in pigs (Yang et al., 2012). Synergic reprogramming of mammalian cells by combined exposure to mitotic Xenopus egg extracts and transcription factors has been demonstrated (Ganier et al., 2011). The maintenance of multipotency in human dermal fibroblasts treated with Xenopus egg extracts was achieved in the presence of exogenous fibroblast growth factor-2 (Kole et al., 2014). Notably, different capacities of meiotic, interphase and mitotic extracts to support transcription and replication suggest that the differential use of the extracts or their use in combination can achieve a higher degree of somatic cell reprogramming. For instance, differentiated erythrocyte nuclei, which replicate inefficiently in Xenopus eggs, were found to reset the chromatin structure for embryonic DNA replication after a single mitotic cell cycle (Lemaitre et al., 2005). Mitotic remodeling in this system involves the reduction of chromatin loop domains and increasing recruitment of replication initiation factors, resulting in a shortening of interorigin spacing typical of early embryo stages. The combined experimental reprogramming approaches require further investigation. We believe that Xenopus egg and oocyte extracts may be very helpful in developing the alternative methods of somatic cell dedifferentiation and reprogramming with a grand purpose to generate pluripotent stem cells in various species.

\section{Acknowledgments}

This review was written with the support, in part, of the Research Fund for Foreign Visiting Professor from Kobe University (to Alexander A. Tokmakov).

\section{References}

ALBERIO R, JOHNSON AD, STICK R, CAMPBELL KH (2005). Differential nuclear remodeling of mammalian somatic cells by Xenopus laevis oocyte and egg cytoplasm. Exp Cell Res 307: 131-141.

AQUILES SANCHEZ J, WONSEY DR, HARRIS L, MORALES J, WANGH L J (1995). Efficient plasmid DNA replication in Xenopus egg extracts does not depend on prior chromatin assembly. J Biol Chem 270: 29676-29681.

ARIAS E E, WALTER J C (2004). Initiation of DNA replication in Xenopus egg extracts. Front Biosci 9: 3029-3045.

BARRETO G, SCHÄFER A, MARHOLD J, STACH D, SWAMINATHAN S K, HANDA V, DÖDERLEIN G, MALTRY N, WU W, LYKO F, NIEHRS C (2007). Gadd45a promotes epigenetic gene activation by repair-mediated DNA demethylation. Nature 445: 671-675.

BHUTANI N, BRADY JJ, DAMIAN M, SACCO A, CORBEL SY, BLAU HM (2010). Reprogramming towards pluripotency requires AID-dependent DNAdemethylation. Nature 463: 1042-1047.

BIAN Y, ALBERIO R, ALLEGRUCCI C, CAMPBELL K H, JOHNSON A D (2009). Epigenetic marks in somatic chromatin are remodelled to resemble pluripotent nuclei by amphibian oocyte extracts. Epigenetics 4: 194-202.

BIDDLE A, SIMEONI I, GURDON J B (2009). Xenopus oocytes reactivate muscle gene transcription in transplanted somatic nuclei independently of myogenic factors. Development 136: 2695-2703.

BIRDA (2002). DNAmethylation patterns and epigenetic memory. Genes Dev16:6-21.

BRIGGS R, KING T J (1952). Transplantation of Living Nuclei From Blastula Cells into Enucleated Frogs' Eggs. Proc Natl Acad Sci USA 38: 455-463.

BYRNE J A, SIMONSSON S, WESTERN P S, GURDON J B (2003). Nuclei of adult mammalian somatic cells are directly reprogrammed to oct- 4 stem cell gene expression by amphibian oocytes. Curr Biol 13:1206-1213.
D'ALESSIO J A, WRIGHT K J, TJIAN R (2009). Shifting players and paradigms in cell-specific transcription. Mol Cell 36: 924-931.

DAVIDSONE H (1986). Gene activity in early development. Academic Press, New York.

DIMITROV S, WOLFFE A P (1996). Remodeling somatic nuclei in Xenopus laevis egg extracts: molecular mechanisms for the selective release of histones $\mathrm{H} 1$ and $\mathrm{H} 1(0)$ from chromatin and the acquisition of transcriptional competence. EMBO J 15: 5897-5906.

DÖRING V, STICK R (1990). Gene structure of nuclear lamin LIII of Xenopus laevis; a model for the evolution of IF proteins from a lamin-like ancestor. EMBO J 9: 4073-4081.

ELSDALE TR, GURDON J B, FISCHBERG M (1960). A description of the technique for nuclear transplantation in Xenopus laevis. J Embryol Exp Morpho/8: 437-444.

FICZ G, BRANCO M R, SEISENBERGER S, SANTOS F, KRUEGER F, HORE T A MARQUES C J, ANDREWS S, REIK W (2011). Dynamic regulation of 5-hydroxymethylcytosine in mouse ES cells and during differentiation. Nature 473: 398-402.

GANIER O, BOCQUET S, PEIFFER I, BROCHARD V, ARNAUD P, PUY A, JOUNEAU A, FEIL R, RENARD J P, MÉCHALI M (2011). Synergic reprogramming of mammalian cells by combined exposure to mitotic Xenopus egg extracts and transcription factors. Proc Natl Acad Sci USA 108: 17331-17336.

GILLESPIE P J, GAMBUS A, BLOW J J (2012). Preparation and use of Xenopus egg extracts to study DNA replication and chromatin associated proteins. Methods 57: 203-213.

GONDA K, FOWLER J, KATOKU-KIKYO N, HAROLDSON J, WUDEL J, KIKYO $N$ (2003). Reversible disassembly of somatic nucleoli by the germ cell proteins FRGY2a and FRGY2b. Nat Cell Biol 5: 205-210.

GONZALEZ M A, TACHIBANA K E, LASKEY R A, COLEMAN N (2005). Control of DNA replication and its potential clinical exploitation. Nat Rev Cancer 5: 135-141.

GURDON J B (1962a). The developmental capacity of nuclei taken from intestinal epithelium cells of feeding tadpoles. J Embryol Exp Morphol 10: 622-640.

GURDON J B (1962b). The transplantation of nuclei between two species of Xenopus. Dev Biol 5:68-83.

GURDON JB (1968). Changes in somatic cell nuclei inserted into growing and maturing amphibian oocytes. J Embryol Exp Morphol 20: 401-414.

GURDON J B (1976). Injected nuclei in frog oocytes: fate, enlargement, and chromatin dispersal. J Embryol Exp Morphol 36: 523-540.

GURDON J B, LASKEY R A, DE ROBERTIS E M, PARTINGTON G A (1979). Reprogramming of transplanted nuclei in amphibia. Int Rev Cytol Suppl. 9: 161-178.

GURDON J B, PARTINGTON G A, DE ROBERTIS E M. (1976) Injected nuclei in frog oocytes: RNA synthesis and protein exchange. J Embryol Exp Morpho/36:541-553.

GURDON JB, UEHLINGERV (1966). "Fertile" intestine nuclei. Nature210: 1240-1241.

GURDON J B, WILMUT I (2011). Nuclear transfer to eggs and oocytes. Cold Spring Harb Perspect Biol 3: a002659.

GÜTTINGER S, LAURELL E, KUTAY U (2009). Orchestrating nuclear envelope disassembly and reassembly during mitosis. Nat Rev Mol Cell Biol 10: 178-191.

HALLEY-STOTT R P, PASQUE V, ASTRAND C, MIYAMOTO K, SIMEONI I, JULLIEN J, GURDON J B (2010). Mammalian nuclear transplantation to Germinal Vesicle stage Xenopus oocytes - a method for quantitative transcriptional reprogramming. Methods 51: 56-65.

HERNANDEZ-VERDUN D (2006). The nucleolus: a model for the organization of nuclear functions. Histochem Cell Biol. 126: 135-148.

JULLIEN J, ASTRAND C, HALLEY-STOTT R P, GARRETT N, GURDON J B (2010). Characterization of somatic cell nuclear reprogramming by oocytes in which a linker histone is required for pluripotency gene reactivation. Proc Natl Acad Sci USA 107: 5483-5488.

JULLIEN J, GURDON J (2011) Reprogramming of gene expression following nuclear transfer to the Xenopus oocyte. Biol Aujourdhui 205: 105-110.

JULLIEN J, PASQUE V, HALLEY-STOTT R P, MIYAMOTO K, GURDON J B (2011). Mechanisms of nuclear reprogramming by eggs and oocytes: a deterministic process? Nat Rev Mol Cell Biol. 12: 453-459.

KIKYO N, WADE P A, GUSCHIN D, GE H, WOLFFE A P (2000). Active remodeling of somatic nuclei in egg cytoplasm by the nucleosomal ATPase ISWI. Science 289: 2360-2362.

KIKYO N, WOLFFE AP (2000). Reprogramming nuclei: insights from cloning, nuclear transfer and heterokaryons. J Cell Sci 113 (Pt 1): 11-20. 
KIMURA H, COOK P R (2001). Kinetics of core histones in living human cells: little exchange of $\mathrm{H} 3$ and $\mathrm{H} 4$ and some rapid exchange of $\mathrm{H} 2 \mathrm{~B}$. J Cell Biol153: 1341-1353.

KOLE D, AMBADY S, PAGE R L, DOMINKO T (2014). Maintenance of multipotency in human dermal fibroblasts treated with Xenopus laevis egg extract requires exogenous fibroblast growth factor-2. Cell Reprogram 16: 18-28.

LASKEY R A, GURDON J B (1970). Genetic content of adult somatic cells tested by nuclear transplantation from cultured cells. Nature 228:1332-1334.

LEMAITRE J M, DANIS E, PASERO P, VASSETZKY Y, MÉCHALI M (2005). Mitotic remodeling of the replicon and chromosome structure. Cell 123: 787-801.

LENO G H, MILLS A D, PHILPOTT A, LASKEY R A (1996). Hyperphosphorylation of nucleoplasmin facilitates Xenopus sperm decondensation at fertilization. J Biol Chem 271: 7253-7256.

MAYER C, NEUBERT M, GRUMMT I (2008). The structure of NoRC-associated RNA is crucial for targeting the chromatin remodelling complex NoRC to the nucleolus. EMBO Rep 9: 774-780.

McKITTRICK E, GAFKEN PR, AHMAD K, HENIKOFF S (2004). Histone H3.3 is enriched in covalent modifications associated with active chromatin. Proc Natl Acad Sci USA. 101: 1525-1530.

MIYAMOTO K, FURUSAWA T, OHNUKI M, GOEL S, TOKUNAGA T, MINAMI N, YAMADAM, OHSUMIK, IMAIH(2007). Reprogramming events of mammalian somatic cells induced by Xenopus laevis egg extracts. Mol Reprod Dev. 74: 1268-1277.

MIYAMOTO K, YAMASHITA T, TSUKIYAMA T, KITAMURA N, MINAMI N, YAMADA M, IMAI H (2008). Reversible membrane permeabilization of mammalian cells treated with digitonin and its use for inducing nuclear reprogramming by Xenopus egg extracts. Cloning Stem Cells 10: 535-542.

MURATA K, KOUZARIDES T, BANNISTER A J, GURDON J B (2010). Histone H3 lysine 4 methylation is associated with the transcriptional reprogramming efficiency of somatic nuclei by oocytes. Epigenetics Chromatin 3: 4 .

NEWPORT J, KIRSCHNER M (1982a). A major developmental transition in early Xenopus embryos: I. characterization and timing of cellular changes at the midblastula stage. Cell 30: 675-686.

NEWPORT J, KIRSCHNER M (1982b). A major developmental transition in early Xenopus embryos: II. Control of the onset of transcription. Cell 30: 687-696.

NG R K, GURDON J B (2008). Epigenetic memory of an active gene state depends on histone H3.3 incorporation into chromatin in the absence of transcription. Nat Cell Biol 10: 102-109.

NIEHRS C (2009). Active DNA demethylation and DNA repair. Differentiation 77: 1-11.

ØSTRUP O, HYTTEL P, KLÆERKE D A, COLLAS P (2011). Remodeling of ribosomal genes in somatic cells by Xenopus egg extract. Biochem Biophys Res Commun 412: 487-493.

ØSTRUP O, PEDERSEN H S, HOLM H M, HYTTEL P (2015). Analysis of nucleolar morphology and protein localization as an indicator of nuclear reprogramming. Methods Mol Biol 1222:161-174.

PETER M, NAKAGAWA J, DORÉE M, LABBÉ J C, NIGG E A (1990) In vitro disassembly of the nuclear lamina and $M$ phase-specific phosphorylation of lamins by cdc2 kinase. Cell 61: 591-602.
POPP C, DEAN W, FENG S, COKUS SJ, ANDREWS S, PELLEGRINI M, JACOBSEN SE, REIKW (2010). Genome-wide erasure of DNA methylation in mouse primordia germ cells is affected by AID deficiency. Nature 463: 1101-1105.

PRUNUSKE A J, ULLMAN K S (2006). The nuclear envelope: form and reformation Curr Opin Cell Biol 18: 108-116.

RATHBONE A J, LIDDELL S, CAMPBELL K H (2013). Proteomic analysis of early reprogramming events in murine somatic cells incubated with Xenopus laevis oocyte extracts demonstrates network associations with induced pluripotency markers. Cell Reprogram 15: 269-280.

RICE J C, ALLIS C D (2001). Histone methylation versus histone acetylation: new insights into epigenetic regulation. Curr Opin Cell Biol 13: 263-273.

RYAN J, LLINAS A J, WHITE D A, TURNER B M, SOMMERVILLE J (1999). Maternal histone deacetylase is accumulated in the nuclei of Xenopus oocytes as protein complexes with potential enzyme activity. J Cell Sci 112: 2441-2452.

SAGATA N, WATANABE N, VANDE WOUDE G F, IKAWA Y (1989). The c-mos protooncogene product is a cytostatic factor responsible for meiotic arrest in vertebrate eggs. Nature 342: 512-518.

SIMARD R (1970). The nucleus: action of chemical and physical agents. Int Rev Cytol 28: 169-211.

SIMONSSONS, GURDON J (2004). DNA demethylation is necessary for the epigenetic reprogramming of somatic cell nuclei. Nat Cell Biol 6: 984-990.

STROHNERR, NEMETHA, JANSAP, HOFMANN-ROHRERU, SANTOROR, LÄNGST G, GRUMMT I (2001) NoRC--a novel member of mammalian ISWI-containing chromatin remodeling machines. EMBO J 20:4892-4900.

STROHNER R, NÉMETHA, NIGHTINGALE KP, GRUMMTI, BECKER PB, LÄNGST $G$ (2004). Recruitment of the nucleolar remodeling complex NoRC establishes ribosomal DNA silencing in chromatin. Mol Cell Biol 24: 1791-1798.

TAMADA H, VAN THUAN N, REED P, NELSON D, KATOKU-KIKYO N, WUDEL J, WAKAYAMA T, KIKYO N (2006). Chromatin decondensation and nuclear reprogramming by nucleoplasmin. Mol Cell Biol 26: 1259-1271.

TAHILIANI M, KOH K P, SHEN Y, PASTOR W A, BANDUKWALA H, BRUDNO Y AGARWAL S, IYER L M, LIU D R, ARAVIND L, RAO A (2009). Conversion of 5-methylcytosine to 5-hydroxymethylcytosine in mammalian DNA by MLL partner TET1. Science 324: 930-935.

TOKMAKOV A A, STEFANOV V E, IWASAKI T, SATO K, FUKAMI Y (2014). Calcium signaling and meiotic exit at fertilization in Xenopus egg. Int J Mol Sci 15 18659-18676

WANGH L J, DEGRACE D, SANCHEZ J A, GOLD A, YEGHIAZARIANS Y, WIEDEMANN K, DANIELS S (1995). Efficient reactivation of Xenopus erythrocyte nucle in Xenopus egg extracts. J Cell Sci 108: 2187-2196.

YANG X, MAO J, WALTERS EM, ZHAO MT, TESON J, LEE K, PRATHER R (2012). Xenopus egg extract treatment reduced global DNA methylation of donor cells and enhanced somatic cell nuclear transfer embryo development in pigs. Biores Open Access 1: 79-87. 


\section{Further Related Reading, published previously in the Int. J. Dev. Biol.}

\section{Nuclear reprogramming in zygotes}

Chanchao Lorthongpanich, Davor Solter and Chin Yan Lim

Int. J. Dev. Biol. (2010) 54: 1631-1640

http://dx.doi.org/10.1387/ijdb.103201cl

Faithful reprogramming to pluripotency in mammals - what does nuclear transfer teach us?

Julien Maruotti, Alice Jouneau and Jean-Paul Renard

Int. J. Dev. Biol. (2010) 54: 1609-1621

http://dx.doi.org/10.1387/ijdb.103195jm

Remodeling of sperm chromatin induced in egg extracts of amphibians

C Katagiri and K Ohsumi

Int. J. Dev. Biol. (1994) 38: 209-216

http://dx.doi.org/10.1387/ijdb.7981030

Generation of pluripotent stem cells via protein transduction

Xia Li, Pengfei Zhang, Chao Wei and Yunhai Zhang

Int. J. Dev. Biol. (2014) 58: 21-27

http://www.ijdb.ehu.es/web/paper/140007XL

Role of the donor nuclei in cloning efficiency: can the ooplasm reprogram any nucleus?

Yoko Kato and Yukio Tsunoda

Int. J. Dev. Biol. (2010) 54: 1623-1629

http://www.ijdb.ehu.es/web/paper/103203yk

Reprogramming of melanoma cells by embryonic microenvironments

Alejandro Díez-Torre, Ricardo Andrade, Cristina Eguizábal, Elixabete López, Jon Arluzea, Margarita Silió and Juan Aréchaga Int. J. Dev. Biol. (2009) 53: 1563-1568

http://www.ijdb.ehu.es/web/paper/093021ad
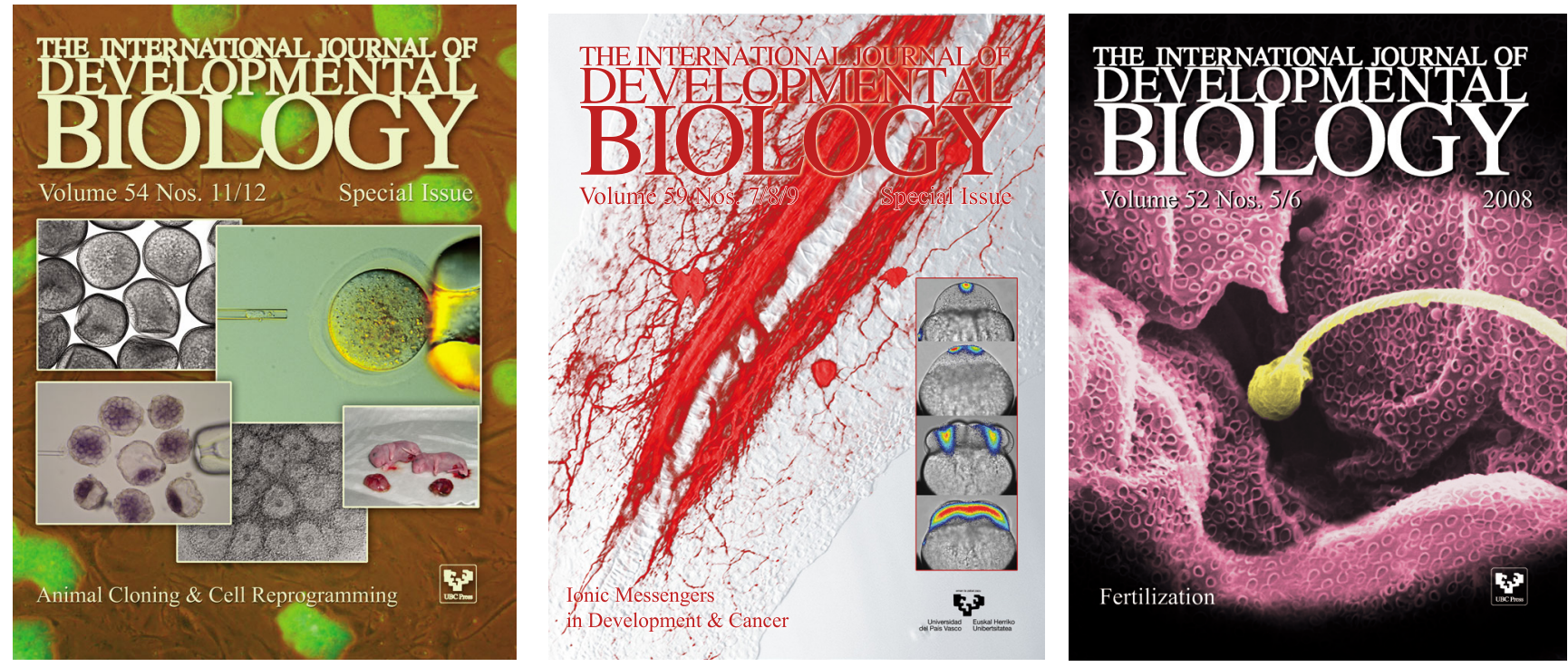